\title{
Portable Electrocardiograph Dengan Sadapan Pada Telapak Tangan Dan Kaki
}

\author{
Muhammad Syifaul Linnas \#, Sumber, Moch.Prastawa A.T.P \\ Jurusan Teknologi Elektro-medis Poltekkes Kemenkes, Surabaya \\ Jl. Pucang Jajar Timur No. 10, Surabaya, 60245, Indonesia \\ \#Syifasieva@gmail.com,sumberrani@gmai.com,,mpatp77@yahoo.com,
}

\begin{abstract}
Info Artikel
Abstrak

Penerimaan Artikel:

Diterima 9 Maret 2019

Revisi 15 Des 2020

Terbit 18 Des 2020

Electrocardiograph (ECG) secara rutin dilakukan oleh operator terampil yang terbiasa dengan penempatan masing-masing elektroda pada pasien. Posisi elektroda yang salah dapat menyebabkan kesalahan kritis dalam diagnosis dan perawatan penyakit jantung. Tujuan dari penelitian ini adalah mendesain sebuah Portable Electrocardiograph dengan Sadapan Pada Telapak Tangan dan Kaki. Kontribusi dari penelitian ini adalah memudahkan orang awam dalam bidang kesehatan dalam hal penggunaan Electrocardiograph. Penelitian ini juga bertujuan mendesain Electrocardiograph yang cukup terjangkau bagi puskesmas/pusat-pusat pelayanan medis di

\section{Kata kunci:}

ECG

Monitoring Jantung

Portable

daerah. Agar desain ini dapat memudahkan dalam metode penggunaan alat, maka dibuatlah alat Electrocardiograph (ECG) dengan elektroda pad yang akan diletakkan pada telapak tangan dan telapak kaki yang telah di berikan tanda pada elektroda tersebut. Electrocardiograph (ECG) menggunakan desain High Pass Filter (HPF) Pasif 20dB ditambah Non Inverting Amplifier, Low Pass Filter (LPF) 40dB, dan notch filter yang akan ditampilkan pada layar monitor Personal Computer (PC). Dari hasil sadapan beberapa responden, terlihat hasil tampilan yang menyerupai/mendekati sinyal Electrocardiograph (ECG) sebenarnya. Kekurangan dari modul ini jika tidak adanya grounding yang baik dari power suply maka akan terjadi noise pada hasil sinyal yang akan ditampilkan. Hasil penelitian ini dapat di implementasikan pada Electrocardiograph (ECG) konvensional untuk meningkatkan kemudahan dalam hal penggunaan alat.

Abstract

Electrocardiograph (ECG) is routinely performed by skilled operators who are familiar with the placement of each electrode in the patient. The wrong electrode position can cause critical errors in the diagnosis and treatment of heart disease. The purpose of this research is to design a Portable Electrocardiograph with leads on the palms and feet. The contribution of this research is to facilitate ordinary people in the field of health in terms of the use of electrocardiograph. This research also aims to design an electrocardiograph which is quite affordable for puskesmas medical service centers in the regions. In order for this design to facilitate the method of using the instrument, an Electrocardiograph (ECG) tool is made with an electrode pad that will be placed on the palm of the hand and the foot that has been marked on the electrode. Electrocardiograph (ECG) uses a 20dB Passive High Pass Filter (HPF) design plus a Non Inverting Amplifier, Low Pass Filter (LPF) of 40dB, and a notch filter that will be displayed on the Personal Computer (PC) monitor screen. From the results of the leads of several respondents, visible results that resemble / approach the actual Electrocardiograph (ECG) signal. Weaknesses of this module if there is no good grounding of power supply, there will be noise on the results of the signal to be displayed. The results of this study can be implemented on conventional Electrocardiograph (ECG) to increase the ease of use of the tool.
\end{abstract}

\section{Penulis korespondensi:}

Moch.Prastawa A.T.P

Departemen Electromedical Teknik

Poltekkes Kemenkes, Surabaya

J1. Pucang Jajar Timur No. 10, Surabaya, 60245, Indonesia

Email: mpatp77@yahoo.com
This work is an open access article and licensed under a Creative Commons Attribution-ShareAlike 4.0 International License (CC BY-SA 4.0).

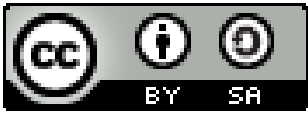

\section{PENDAHULUAN}

Sinyal elektrokardiogram (EKG) telah terbukti menjadi biometrik potensial untuk digunakan dalam diagnosa aritmia ataupun patologi pada tubuh manusia [1] [2] [3] [4] [5]. Minat khusus untuk analisis EKG berasal dari perannya sebagai metode investigasi noninvasif yang efisien [6]. Salah satu informasi penting yang dapat diambil dari sinyal ECG adalah aktivitas kelistrikan jantung yang membentuk gelombang PQRST [7] [8]. Pengerjaan pada biometrik EKG telah melihat fajar yang baru melalui pengenalan "off-the-person" sensing, yang membuat penerimaan ECG sebanding yang ditemukan di modalitas yang lebih mapan seperti iris, sidik jari, telapak tangan, dan sebagainya [9] [10]. Klinis bandwidth dari sinyal EKG adalah 0,05 hingga $125 \mathrm{~Hz}$, sedangkan bandwidth pemantauan adalah 0,5 hingga $50 \mathrm{~Hz}$ [11] [12]. Alat electrocardiograph yang terdapat di rumah sakit tipe $\mathrm{A}$ atau tipe B harganya cukup mahal, dan sangat sulit untuk dijangkau oleh pusat-pusat pelayanan medis di daerah. Selain itu umumnya alat ini berukuran besar, sehingga sangat sulit untuk 
memberikan pelayanan dari rumah kerumah sesuai program puskesmas yang selama ini sudah berjalan, sehingga kondisi ini kurang efektif.

Perancangan mesin ECG telah dilakukan oleh beberapa peneliti dari sisi proses maupun pengiriman data. Rohadatul Aisy merancang sebuah ECG yang dapat menampilkan hasil yang ditampilkan di personal computer [18]. Akan tetapi pengembangan yang dilakukan Rohadatul Aisy ini masih belum berbentuk portable. Aziz melakukan pengembangan dengan menggunakan bentuk portable [20]. Yunarni melakukan pengembangan menggunakan sistem yang berbasis arduino [19]. Akan tetapi pengembangan yang di lakukan Yunarni masih belum menggunakan sistem portable. Dari semua pengembangan tersebut masih menggunakan metode penyadapan konvensional dan tentu saja butuh tenaga medis yang kompeten untuk melakukan perekaman ataupun pemantauan sinyal ECG.

Berdasarkan uraian studi pustaka yang telah diuraikan, maka ada beberapa hal yang perlu diselesaikan melalui sebuah penelitian antara lain perancangan alat yang belum menggunakan sistem portable, masih menggunakan penyadapan konvensional $(\mathrm{AgCl})$, dan belum menggunakan komputer sebagai pengolah data/penampil data rekaman ECG. Oleh karena itu, pada penelitian ini akan dirancang Portable Electrocardiograph dengan Sadapan pada Telapak Tangan dan Kaki dengan tujuan memperbaiki kekurangan dari penelitian sebelumnya. Penggunaan rancangan ini lebih efektif karena memiliki kelebihan dalam hal sistem yang sudah portable dan kompatibel dengan Mikrokontroller Arduino dengan interface yang mampu ditampilkan pada komputer secara real time. Perbedaan mendasar dari ECG yang dibuat sebelumnya adalah sensor elektroda dan output display yang dipilih yaitu sistem komputer untuk mempermudah pengolahan data [14] [8]. Penelitian ini juga mengembangkan dari segi penyadapan dengan melakukan penyadapan pada telapak tangan dan kaki menggunakan elektroda plat aluminium yang telah di cantumkan tanda bagian tubuh yang akan di sadap, tangan kanan dan tangan kiri atau kaki kanan dan kaki kiri.

Artikel ini terdiri dari 5 bagian, bagian 2 berisi bahan beserta metode pengembangan yang akan dilakukan. Bagian 3 merupakan hasil-hasil yang di lakukan pada penelitian ini, bagian 4 adalah diskusi, dan bagian 5 adalah kesimpulan pada penelitian ini.

\section{BAHAN DAN METODE}

\section{A. Susunan Percobaan}

Penelitian ini menggunakan subyek dewasa dengan kriteria sebagai responden berusia 15-65 tahun. Pengukuran dilakukan pada 2 responden dengan pengambilan data masing-masing 1 kali.

\section{1) Alat dan Bahan}

Penelitian ini menggunakan IC TL084CN (Operational Amplifiers Series, Texas Instrument, America) sebagai penguat sinyal sadapan utama dan Elektroda pad logam aluminium sebagai Elektroda. Penelitian ini juga menggunakan multiplexer HP4067 (Analog Switches/Muxes, Texas Instrument, America) sebagai pemilih input pada rangkaian instrument. Penelitian ini menggunakan Step up Module xl6009e1 (Adjustable converter Power suply series, Xlsemi, China) dan Reverse Module MC34063AP (Peak Boost/Buck/Inverting Switching Regulators Series, Texas Instrument, America) sebagai pengatur tegangan input utama. Penelitian ini memakai 4 Lithium Battery sebagai sumber daya utama. Output Rangkaian instrumen beserta filter akan diolah oleh microcontroller dengan menggunakan Arduino UNO (UNO Series, Arduino IDE, Italy) dan hasilnya akan tampil pada layar PC.

\section{2) Percobaan}

Pada penelitian ini dilakukan pengukuran langsung pada responden. Dilakukan pengukuran pada 2 responden dengan masing-masing pengambilan datanya sebanyak 1 kali.

\section{B. Blok diagram}

Pasien meletakkan telapak tangan dan telapak kaki pada elektroda sesuai dengan tempat yang telah di tetapkan. Rangkaian instrumentasi akan menyadap sinyal kelistrikan dari pasien yang telah dihantarkan oleh elektroda. Sinyal yang masih mentah dari instrumentasi akan di proses sedemikian rupa oleh filter guna menghilangkan noise yang ikut tersadap. Sinyal yang telah difilter akan di kuatkan menggunakan rangkaian PSA. Sinyal yang telah diperkuat akan di inputkan pada mikrokontroller agar dapat di proses menjadi data digital. Data dari pasien yang telah di proses sedemikian rupa akan di inputkan dan di tampilkan di PC secara real time.

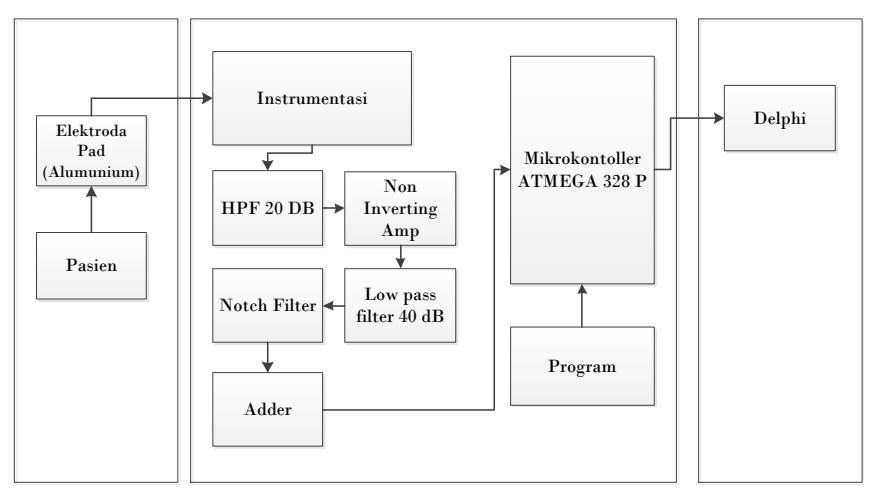

Fig. 1. Diagram Blok ECG

\section{Diagram Alir}

Pada diagram alir di bawah setelah tombol start ditekan maka terjadi proses inisialisasi. Elektroda dari setiap lead akan menyadap sinyal kelistrikan jantung yang akan di proses oleh instrument ECG. Kemudian hasil data sinyal kelistrikan jantung yang berupa sinyal analog akan di ubah menjadi data digital pada mikrokontroller guna dilakukannya pemrosesan data. Data yang telah diproses akan di tampilkan pada PC. Ketika tombol stop di tekan, maka alat akan berhenti bekerja.

\section{Jurnal TEKNOKES}




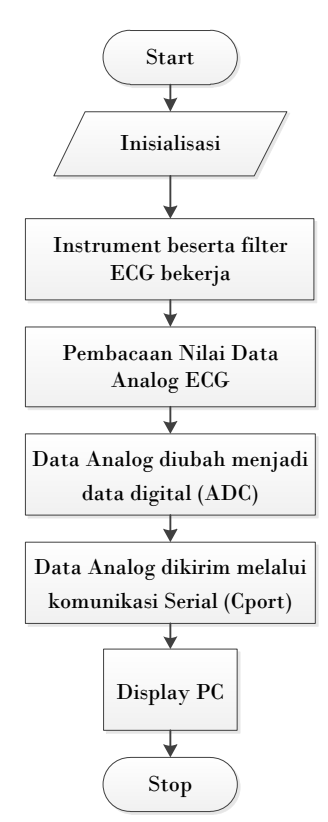

Fig. 2. Diagram Alir Electrocardiograph

\section{Rangkaian Analog}

1) Rangkaian Instrumen Amplifier

Pada fig 3 dibawah adalah rangkaian instrumen amplifier. Rangkaian instrument amplifier merupakan suatu rangkaian penguat elektronika dengan hambatan arus searah yang memiliki gain (faktor penguat). Rangkaian ini digunakan untuk menguatkan proses pengolahan sinyal tubuh yang sudah disadap oleh elektroda. Penguatan tinggi diperlukan untuk memperkuat sinyal ECG, yang berkisar $1 \mathrm{mV}$, ke sinyal yang dapat dibaca oleh ADC (analog to digital converter) yang berkisar $0-5 \mathrm{~V}$. Pada rangkaian instrument amplifier outputnya masih terdapat noise. Output pada rangkaian penguat instrumen akan masuk ke rangkaian high pass filter dan non inverting untuk mengurangi noise. Penguat instrumen sebenarnya adalah gabungan dari penguat diferensial yang memperkuat beda tegangan antara dua terminal masukan OpAmp.

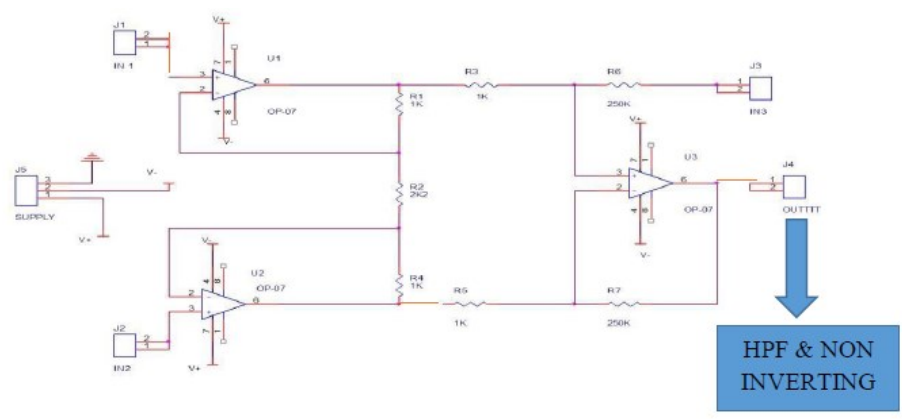

Fig. 3. Rangkaian Instrumen Amplifier

2) Rangkaian Filter HPF Pasif 20dB dan Non Inverting Amplifier
Pada fig 4 dibawah adalah rangkaian Filter HPF Pasif $20 \mathrm{~dB}$ dan Non Inverting Amplifier.Rangkaian high pass filter adalah filter yang melewatkan frekuensi diatas frekuensi cut off. Rangkaian HPF yang paling sederhana tersusun atas kapasitor yang terhubung secara paralel dengan resistor. Karena sinyal ECG berkisar antara $0,05100 \mathrm{~Hz}$ maka diperlukan rangkaian HPF untuk melewatkan sinyal diatas $0,05 \mathrm{~Hz}$. Rangkaian filter HPF pasif $20 \mathrm{~dB}$ menggunakan frekuensi cut off sebesar $3,38 \mathrm{~Hz}$. Selain itu rangkaian ini merupakan gabungan dari rangkaian filter HPF dan non inverting amplifier. Rangkaian ini merupakan filter pasif karena menggunakan potensio sebagai variable resistor. Output dari HPF akan masuk ke rangkaian LPF 40db karena masih terdapat banyak noise.

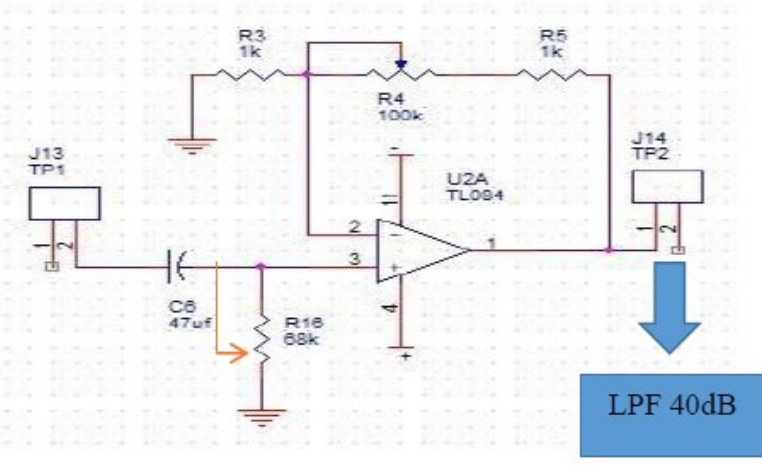

Fig. 4. Rangkaian Filter HPF Pasif 20dB dan Non Inverting Amplifi

\section{3) Rangkaian Low Pass Filter 40dB}

Pada fig 5 dibawah adalah Rrangkaian Low Pass Filter. Low pass filter (LPF) adalah salah satu filter yang melewatkan frekuensi dibawah frekuensi cut off. Pada low pass filter yang ideal, sinyal dengan frekuensi diatas frekuensi cut off tidak akan dilewatkan sama sekali dimana $\mathrm{Vo}_{0}=0$ volt. Rangkaian ini menggunakan IC TL084, dimana output dari rangkaian ini akan masuk ke notch filter.

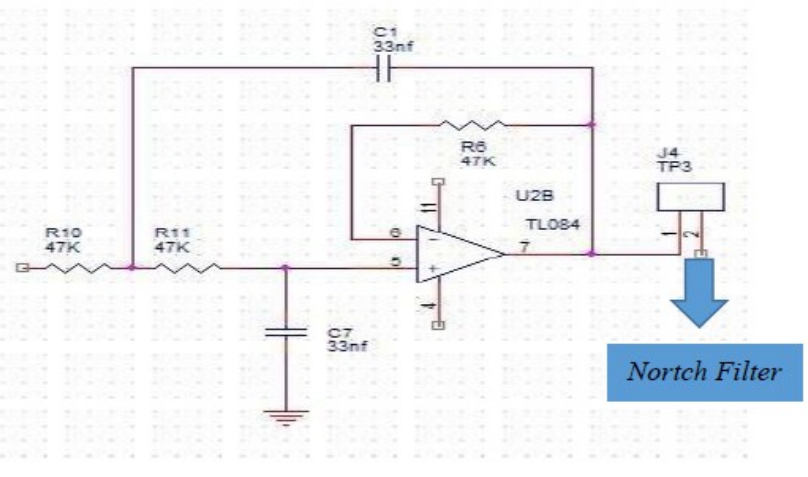

Fig. 5. Rangkaian Low Pass Filter 40dB 
Pada fig 6 dibawah adalah Rangkaian Notch Filter.

Notch filter adalah salah satu filter yang memiliki karekteristik untuk menahan sinyal dengan frekuensi sesuai frekuensi cut off dan akan melewatkan sinyal diluar frekuensi cut off. Rangkaian ini mengunkan IC TL 084 dimana output dari rangkaian ini akan masuk ke rangkaian low pass filter.

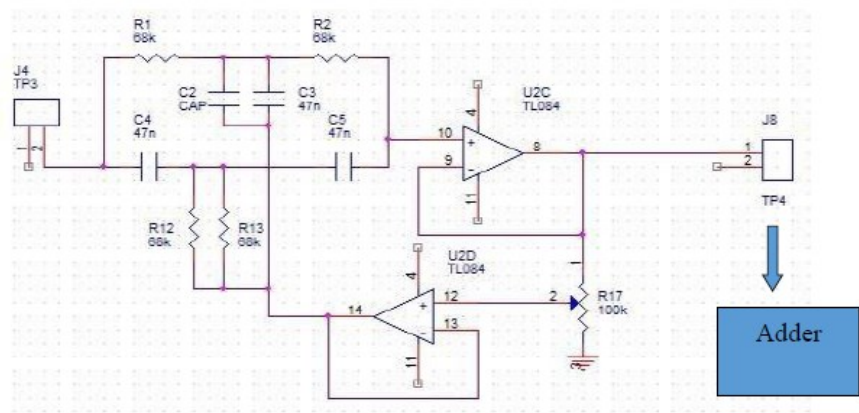

Fig. 6. Rangkaian Notch Filter

\section{5) Rangkaian Adder}

Pada fig 7 dibawah adalah rangkaian Adder. Rangkaian adder adalah rangkaian yang berfungsi untuk menaikkan level tegangan pada sinyal ECG dimana sebagian dari sinyal ECG naik menjadi positif seluruhnya. Tujuan dari rangkaian ini, agar tegangan sinyal ECG dapat tersampling secara utuh oleh ADC. Rangkaian ini menggunakan dioda zener sebagai clamper dan VR (variable resistor sebagai setting tegangan Vref).

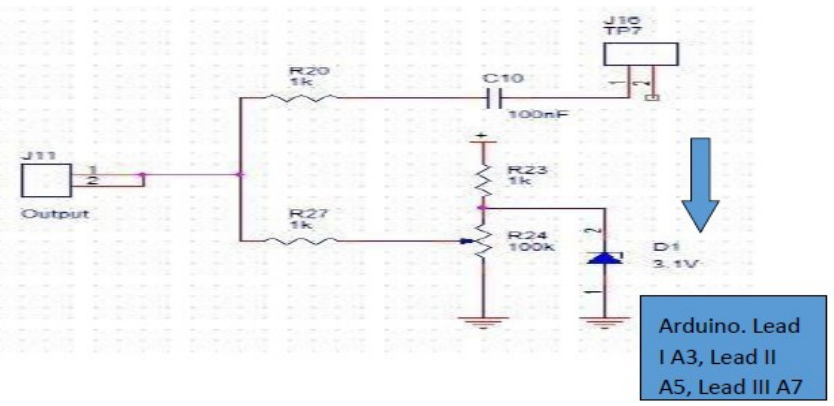

Fig. 7. Rangkaian Adder

\section{HASIL}

1) Desain Modul

Dapat di lihat desain gambar pada Fig. 8 menunjukkan bahwa bagian kabel elektroda yang sudah terhubung langsung ke dalam rangkaian sehingga tidak akan bisa tertukar/terbalik pada saat proses penggunaan modul. Hal ini bertujuan untuk mempermudah penggunaan orang

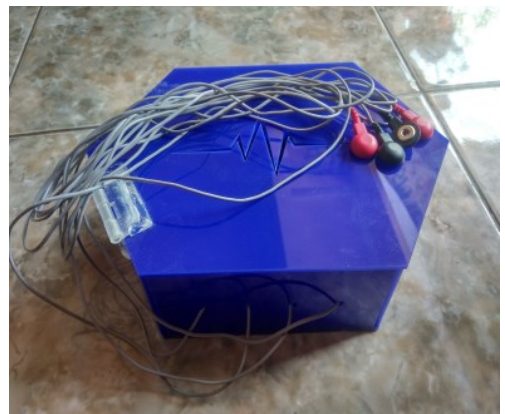

Fig. 8. Perancangan Portable Electrocardiograph

\section{2) Listing Program Pada Arduino}

Program dibawah menggunakan aplikasi arduino dan memakai board arduino UNO. Program ini mengatur setiap PIN yang akan dibutuhkan untuk menjalankan modul ECG. Input sinyal analog dari instrumen dan filter ECG akan masuk pada PIN A3. PIN nomor 14,15, dan 16 menjadi input logika dari push button yang berguna untuk memerintahkan board Arduino mengeluarkan logika sesuai koding diatas menuju multiplexer. PIN digital Arduino 6-9 terkoneksi dengan input logika Multiplexer A PIN S0-S3, sedangkan PIN digital Arduino 10-13 terkoneksi dengan input logika Multiplexer B PIN S0-S3. Listing program ini digunakan untuk mengatur multiplexer agar mengeluarkan input yang diinginkan.

\section{Listing program Arduino}

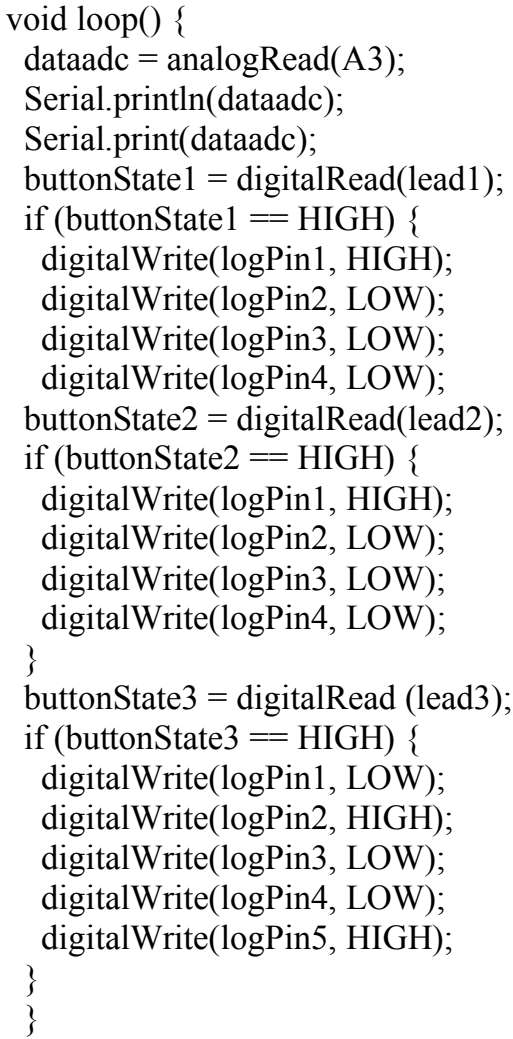




\section{3) Hasil pengukuran sinyal ECG}

Hasil grafik dari lead 1, 2, dan 3 diambil sekali setiap lead. Hasil dari grafik 1 pada fig 9 menampilkan grafik yang masih dipenuhi sinyal noise. Hal ini dikarenakan pada saat pengambilan data yang bertempat di rumah kediaman penulis tidak menggunakan sistem grounding. Maka grafik sinyal yang dihasilkan pun masih mengandung noise dan tidak maksimal.

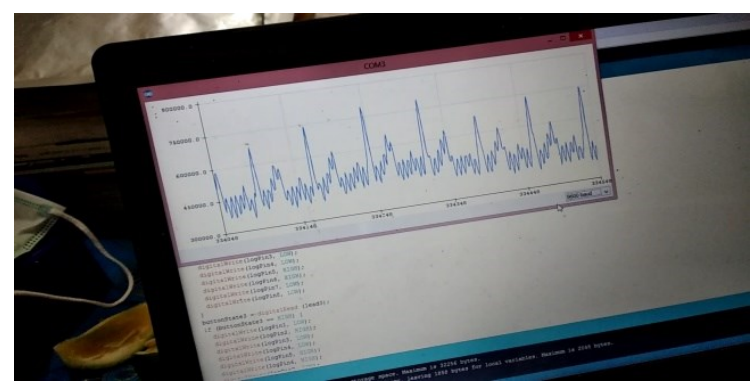

Fig. 9. Pengambilan Data Pada Lead 1

Hasil dari grafik 2 pada fig 10 menampilkan grafik yang sudah bersih dari noise. Hal ini dikarenakan pada saat pengambilan data yang bertempat di Lab Life support Teknik Elektromedik Poltekkes Kemenkes Surabaya yang sudah menggunakan sistem grounding. Maka grafik sinyal yang dihasilkan sudah terbebas dari noise.

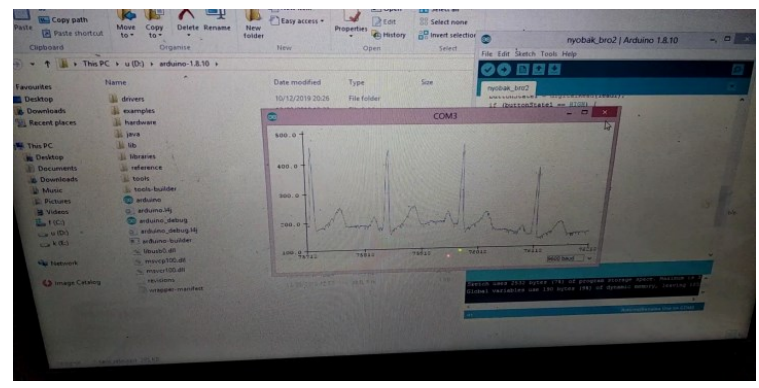

Fig. 10. Pengambilan Data Pada Lead 2

Hasil dari grafik 3 pada fig 11 menampilkan grafik yang masih dipenuhi sinyal noise sama seperti grafik 1 . hal Ini dikarenakan pengambilan data yang bersamaan di tempat yang sama. Maka menghasilkan grafik yang serupa.

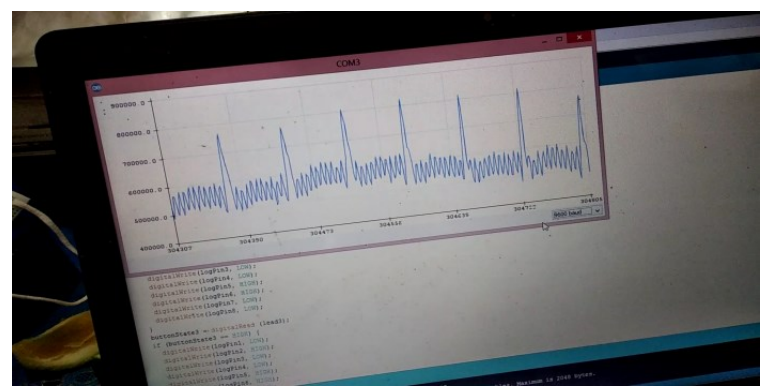

Fig. 11. Pengambilan Data Pada Lead 3

\section{DISKUSI}

Electrocardiograph yang banyak digunakan dirumah sakit memiliki masalah pada pemasangan elektroda yang membutuhkan tenaga medik yang terampil. Orang awam dalam bidang kesehatan akan kebingungan dengan tata cara pemasangan elektroda ECG yang baik dan benar. Dengan dibuatnya Portable Electrocardiograph Dengan Sadapan Pada Telapak Tangan Dan Kaki akan memudahkan para pengguna dalam hal pemakaian. Pada penelitian ini menggunakan elektroda plat baja yang sudah ditandai, tangan kanan dan tangan kiri atau kaki kanan dan kaki kiri. Modul ini juga menggunakan sistem portable untuk mempermudah mobilitas dari Modul itu sendiri, sehingga dapat bekerja tanpa kabel yang mensuplay daya dari jala-jala PLN.

Berdasarkan beberapa temuan penelian sebelumnya yang dilakukan oleh Rohadatul Aisy merancang sebuah ECG yang dapat menampilkan hasil yang ditampilkan di personal computer [18]. Akan tetapi pengembangan yang dilakukan Rohadatul Aisy ini masih belum berbentuk portable. Pada penelitian ini juga menggunakan Personal Computer sebagai penampil hasil pengolahan data. Aziz melakukan pengembangan dengan menggunakan bentuk portable [20]. Penelitian ini juga sudah menggunakan sistem portable mengikuti metode dari penelitian dari Aziz. Yunarni melakukan pengembangan menggunakan sistem yang berbasis arduino [19]. Akan tetapi pengembangan yang di lakukan Yunarni masih belum menggunakan sistem portable. Pada penelitian ini juga menggunakan sistem yang berbasis Arduino akan tetapi sudah berbentuk portable. Dari semua pengembangan tersebut masih menggunakan metode penyadapan konvensional dan tentu saja butuh tenaga medis yang kompeten untuk melakukan perekaman ataupun pemantauan sinyal ECG. Dengan dibuatnya Portable Electrocardiograph Dengan Sadapan Pada Telapak Tangan Dan Kaki akan memudahkan para pengguna dalam hal pemakaian.

Pada perancangan alat ini terdapat beberapa kelemahan. Kekurangan dari modul ini jika tidak adanya grounding yang baik dari power suply maka akan terjadi noise pada hasil sinyal yang akan ditampilkan. Personal Computer yang digunakan harus terpasang ke jala-jala PLN yang memiliki Grounding yang bagus.

\section{KESIMPULAN}

Tujuan penelitian ini adalah membuat Electrocardiograph yang menggunakan sensor yang dapat dimengerti bahkan oleh orang awam dalam bidang kesehatan, serta menggunakan sistem portable. Pada penelitian ini menggunakan elektroda plat baja yang sudah ditandai, tangan kanan dan tangan kiri atau kaki kanan dan kaki kiri sehingga dapat dikenali dengan mudah. Dibuatnya modul alat ini juga dapat menggantikan peran Eletrocardiograph yang terlalu mahal pada daerah tertentu dan memiliki prinsip kerja yang sama dengan bantuan komputer/pc yang terinstal program sebagai display utama. Pengambilan data pada responden mengharuskan dalam keadaan yang rileks. Hasil modul sejauh 
ini telah dapat dilakukan pengambilan data pada pasien atau responden dengan syarat input tegangan PC harus memiliki Grounding yang bagus agar sinyal yang di hasilkan dapat maksimal. Dari hasil sadapan beberapa responden, terlihat hasil tampilan yang menyerupai/mendekati sinyal ECG sebenarnya. Pada penelitian kedepannya dapat di buat modul alat yang memiliki display tersendiri, tidak menggunakan pc agar pemakaian dapat lebih efisien. Kemudian juga bisa ditambahkan BPM agar dapat menampilkan hasil diagnosa yang lebih komplit.

\section{Daftar Pustaka}

[1] H. Li, X. Wang, L. Chen, and E. Li, "Denoising and R-peak detection of electrocardiogram signal based on EMD and improved approximate envelope," Circuits, Syst. Signal Process., vol. 33, no. 4, pp. 1-17, 2014, doi: 10.1007/s00034-013-9691-3.

[2] Y. Chen and W. Chen, "Finger ECG based Two-phase Authentication Using 1D Convolutional Neural Networks," Proc. Annu. Int. Conf. IEEE Eng. Med. Biol. Soc. EMBS, vol. 2018-July, pp. 1-4, 2018, doi: 10.1109/EMBC.2018.8512263.

[3] S. K. Yadav, R. Sinha, and P. K. Bora, "Electrocardiogram signal denoising using non-local wavelet transform domain filtering," IET Signal Process., vol. 9, no. 1, pp. 1-9, 2016, doi: 10.1049/iet-spr.2014.0005.

[4] S. Francisco, C. Springs, E. David, O. City, S. Francisco, and R. U. S. A. Data, "ELECTROCARDOGRAM SIGNAL DETECTION," US 9.254,095 B2, 2016.

[5] M. Blanco-Velasco, B. Weng, and K. E. Barner, "ECG signal denoising and baseline wander correction based on the empirical mode decomposition," Comput. Biol. Med., vol. 38, no. 1, pp. 1-13, 2008, doi: 10.1016/j.compbiomed.2007.06.003.

[6] R. V Andreão, B. Dorizzi, and J. Boudy, "ECG Signal Analysis Through Hidden Markov Models," vol. 53, no. 8, pp. 1-9, 2006.

[7] Y. C. Yeh and W. J. Wang, "QRS complexes detection for ECG signal: The Difference Operation Method," Comput. Methods Programs Biomed., vol. 91, no. 3, pp. 1-10, 2008, doi: 10.1016/j.cmpb.2008.04.006.

[8] D. Permana, W. S. M. Sanjaya, and H. Aliah, "Desain dan Implementasi Perancangan Elektrokariograf (EKG) Berbasis Bluetooth," Al-HAZEN J. Phys., vol. 2, no. 1, pp. 1-9, 2015, [Online]. Available: http://journal.uinsgd.ac.id/index.php/ahjop/article/view/309.

[9] H. P. Da Silva, A. Fred, A. Lourenco, and A. K. Jain, "Finger ECG signal for user authentication: Usability and performance," IEEE 6th Int. Conf. Biometrics Theory, Appl. Syst. BTAS 2013, vol. 1, no. 1, pp. 1-8, 2013, doi: 10.1109/BTAS.2013.6712689.
[10] . S. A. B., "Finger Touch Based Ecg Monitoring," Int. J. Res. Eng. Technol., vol. 05, no. 07, pp. 1-4, 2016, doi: 10.15623/ijret.2016.0507040.

[11] P. Wangmo, G. Ramyavani, K. S. Iyer, and V. Karthik Raj, "Two electrode ECG and EOG system for monitoring applications," Int. J. Innov. Technol. Explor. Eng., vol. 8, no. 11, pp. 1-4, 2019, doi: 10.35940/ijitee.K1315.0981119.

[12] F. Purwanda, "Rancang Bangun Elektrokardiograf Menggunakan Mikrokontroler Untuk Mendeteksi Ketidaknormalan Jantung," vol. 44, no. 12, pp. 1-19, 2019, doi: 10.19540 /j. cnki. cjcmm. 20190128. 002.

[13] A. Joseph, "WIRELESSELECTRODE ARRANGEMENT AND METHOD FOR PATIENT MONITORING VAELECTROCARDOGRAPHY," vol. 2, no. 12, pp. 1-20, 2011.

[14] D. Liawatimena, "Portable Elektrocardiograph," Tek. Komuter, vol. 19, no. 2, pp. 1-9, 2011.

[15] W. E. G. S. EAL, "ELECTROCARDIOGRAPH," 2,674,992, 1954.

[16] Anmelder, "COMBINATION OF ELECTROCARDIOGRAM,” WO 94/18890, 1994.

[17] M. Yunus, A. Talib, and A. Khan, "Designing a 3-Lead Cost Effective Ecg Recording Glove for Home Monitoring," Biosci. Eng. An Int. J., vol. 1, no. 1, p. 45, 2014.

[18] Rohadatul 'Aisy, "Cardiac Monitor Berbasis Personal Computer (PC) Parameter Electrocardiograph (ECG,” vol. 1, no. 0, pp. 1-12, 2016.

[19] S. Yunarni, "RANCANG BANGUN EKG 3 CHANNEL BERBASIS ARDUINO,” pp. 1-9, 2017.

[20] A. Aziz, "MONITORING EKG 3 CHANNEL BERBASIS PERSONAL KOMPUTER (Atfirul,”pp. 1-8, 2016. 